\title{
O ENSINO MÉDIO NO ESTADO DO PARÁ: OS INDICADORES DE OFERTA NAS REGIÕES DE INTEGRAÇÃO DO MARAJÓ E METROPOLITANA DE BELÉM NO ANO DE 2014
}

\author{
Gean Ferreira NORONHA ${ }^{1}$ \\ Universidade Federal do Pará - UFPA \\ gean.noronha@hotmail.com \\ Ronaldo Marcos de Lima ARAÚJO² \\ Universidade Federal do Pará - UFPA \\ ronaldolimaaraujo@gmail.com \\ Ana Maria Raiol da COSTA ${ }^{3}$ \\ Universidade Federal do Pará - UFPA \\ anaraioldavi@gmail.com
}

Resumo: Este trabalho tem como objetivo analisar a oferta do ensino médio público nas Regiões de Integração do Marajó $e$ Metropolitana de Belém no ano de 2014. Nos procedimentos, foi adotada a pesquisa bibliográfica, além de contar com o banco de dados do INEP. Os resultados revelam que o número de matrículas do ensino médio vem desacelerando. Foi evidenciada a precariedade das condições de acesso e permanência dos nossos estudantes, além dos insuficientes serviços públicos prestados na escola. Os jovens que dependem do ensino médio público paraense são alijados do processo educacional. Isso compromete um de seus direitos sociais, educação básica pública, obrigatória e de qualidade. A conclusão aponta que o enfrentamento desta problemática exige grandes investimentos em educação, por parte do Governo do Estado do Pará, para que concretamente se encaminhe um Ensino Médio público com qualidade.

Palavras-chave: Ensino Médio. Regiões de Integração. Pará, Indicadores Educacionais.

\begin{abstract}
This work aims to analyze, from the INEP database, the offer of public secondary education in the Integration Regions of Marajo and Metropolitana de Belém, in the year 2014. It is a bibliographical research, characterized as Quantitative. The results of this research reveal that the number of high school enrollments has been slowing down, as well as the precariousness of the conditions of access and permanence of our students, as well as the public services provided in the school. Many young people who depend on public education are left out of the educational process, which compromises their basic social right to offer and guarantee a compulsory, free and quality basic education. We conclude that, in order to deconstruct this scenario, there is a need for large investments by the Government of Pará in quality public secondary education.
\end{abstract}

Keywords: High School. Integration Regions. Pará. Educational Indicators.

\footnotetext{
${ }^{1}$ Graduado em Pedagogia no ano de 2016. Membro do Grupo de Estudos e Pesquisas em Trabalho e Educação, GEPTE.

2 Doutorado em Educação pela Universidade Federal de Minas Gerais, (2000). Professor Associado da Universidade Federal do Pará, Brasil.

${ }^{3}$ Mestrado em Educação pela Universidade Federal do Pará, (2012). Professora do Secretaria Estadual de Educação do Pará , Brasil.
} 


\section{Introdução}

O presente Trabalho apresenta resultados da pesquisa desenvolvida no âmbito do Programa Institucional de Bolsas de Iniciação Científica (PIBIC). Tem por objetivo geral, analisar, a partir do banco de dados do INEP, a oferta do ensino médio público nas Regiões de Integração do Marajó e Metropolitana de Belém no ano 2014.

Quanto aos procedimentos metodológicos, foi adotada a pesquisa bibliográfica, revisando referenciais pautados na perspectiva da Filosofia da Práxis e da Pedagogia Histórico-Crítica. Em seguida, foram levantados os indicadores educacionais do Banco de Dados do INEP sobre o ensino médio no Estado Pará. Por fim, a Tabulação e análise desses dados. O recorte dos dados concentrou-se nas Regiões de Integração do Marajó e da área Metropolitana de Belém. Os critérios desse procedimento foram definidos em função da desigualdade social e econômica que há entre essas regiões.

De acordo com os dados e indicadores sociais da SEPLAN/IBGE (2015), as regiões do Marajó e Metropolitana de Belém apresentam dois extremos do Estado do Pará. Uma é considerada a região mais rica (Belém), a outra avaliada como sendo a mais pobre (Marajó). A região do Marajó apresenta a maior taxa de pobreza do Estado, no ano de 2.000 foi de 68,35\%; em 2010 com 64,14\%. Em contrapartida, a Região Metropolitana apresenta a menor taxa de pobreza com 28,13\% em 2.000, para 19,26\% em 2010. E apresenta uma menor taxa de analfabetismo, de 15 anos ou mais entre as RI com 4\%. Esse foi um dos pontos que chamou atenção para focar a pesquisa nessas duas regiões do Estado do Pará.

\section{Ensino médio: Situando a questão da qualidade}

A LDB (Lei de Diretrizes e Bases da Educação Nacional) de nº 9.394/96 anuncia que o ensino médio deve preparar o educando para o trabalho e para a cidadania, ou seja, promover, no aluno, o desenvolvimento da autonomia intelectual e emocional, necessária para a sua vida em comunidade. Entretanto, destaca-se que o Ensino Médio é marcado pelo dualismo educacional, entendido como dois tipos ou formas de ensino que ora se volta para formação profissional (trabalho), ora se direciona para a preparação do estudante para a universidade. Sobre essa etapa de ensino, Frigotto, Ciavatta e Ramos (2005) apontam que

[...] É neste nível de ensino que se revela com mais evidência a contradição fundamental entre o capital e o trabalho, expressa no falso dilema de sua identidade: destina-se à formação propedêutica ou à preparação para o trabalho? A história nos permite maior clareza sobre a questão, porque vai revelar a ordenação da sociedade em classes que se distinguem pela 
apropriação da terra, da riqueza que advém da produção social e da distribuição dos saberes. (p.31).

Essa dualidade aparece como uma marca característica do ensino médio na educação brasileira e se configura enquanto uma problemática que despertou o interesse em aprofundar os dados do Banco do INEP sobre essa etapa da educação básica em sua relação com a questão da qualidade.

Sobre a qualidade da educação, Dourado (2007) alerta em relação à visão polissêmica que o assunto pode trazer. Segundo esse autor, há inúmeras categorias, perspectivas e elementos sobre o referido tema. Essas diversas perspectivas são utilizadas para qualificar, avaliar e precisar, o que se pensa e o que se deseja no processo educativo quando se trata do tema da educação de qualidade.

Seguindo as ponderações de Dourado (2007), o enfoque tratado neste artigo se refere a uma dimensão de qualidade - ao nível do sistema - das condições de oferta do ensino. Essa dimensão é aqui adotada para, posteriormente, conceituar e analisar a condição da oferta de uma educação com qualidade nas Regiões de Integração do Marajó e Metropolitana.

Vale ressaltar que o aspecto das condições de oferta do ensino envolve diversos elementos, como o espaço físico, serviços oferecidos, equipamentos, bibliotecas, laboratórios específicos, áreas de convivência, de recreação e de práticas desportivas, dentre outros, por representarem importantes elementos para a construção de uma educação de qualidade. Para a análise dessa dimensão, destacam-se dados do Censo Escolar (2014), referentes aos aspectos de Alimentação, Serviços, Dependências, Equipamentos e Tecnologia. Esclarece-se que as coletas referem-se ao ensino médio público paraense da rede estadual, das zonas rural e urbana. Quanto aos dados referentes aos indicadores educacionais do ensino médio no Estado do Pará aparecem os resultados a seguir.

\section{- Número de Matriculas no Ensino Médio no Estado do Pará}

Quando se trata do número de matrículas no Estado do Pará, os indicadores apontam queda de -1,5\% de alunos matriculados no ensino médio regular nos anos de 2010, 2012 e 2014, como aponta a tabela 1. 
Tabela 1- Números de Matrícula do Ensino Médio Regular. Pará. 2010, 2012 e 2014

\begin{tabular}{c|c|c|c|c|c} 
Abrangência & \multirow{2}{*}{ Dependência } & $\begin{array}{c}\text { Total } \\
\text { Ensino } \\
\text { Médio - } \\
\mathbf{2 0 1 0}\end{array}$ & $\begin{array}{c}\text { Total } \\
\text { Ensino } \\
\text { Médio - } \\
\mathbf{2 0 1 2}\end{array}$ & $\begin{array}{c}\text { Total } \\
\text { Ensino } \\
\text { Médio - } \\
\mathbf{2 0 1 4}\end{array}$ & $\begin{array}{c}\text { D\% } \\
\mathbf{2 0 1 0 / 2 0 1 4}\end{array}$ \\
\hline Pará & Estadual & 324.903 & 318.015 & 320.176 & $-1,5$ \\
\hline
\end{tabular}

Nota1: (*) incluir todos os municípios marajoaras

Nota2: Os dados da tabela acima são números absolutos das matrículas do ensino médio regular

Fonte: Brasil / INEP (2010, 2012 e 2014)

Elaboração: OBEDUC (UFPA/UFPE/UFMG)

Na contramão desse índice, estão as matrículas da Educação de Jovens e Adultos - EJA de Nível Médio, já que, no mesmo período, houve aumento em torno de $4,1 \%$, indicando que esta modalidade vem crescendo no Estado do Pará. A EJA contribui para a elevação da escolaridade da população. Como se observa na Tabela 2 , a seguir.

Tabela 2- Números de Matricula da EJA Médio. Pará. 2010, 2012 e 2014.

\begin{tabular}{c|c|c|c|c|c}
\hline Abrangência & Dependência & $\begin{array}{c}\text { EJA Médio } \\
\mathbf{- 2 0 1 0}\end{array}$ & $\begin{array}{c}\text { EJA Médio } \\
\mathbf{- 2 0 1 2}\end{array}$ & $\begin{array}{c}\text { EJA Médio } \\
\mathbf{- 2 0 1 4}\end{array}$ & $\begin{array}{c}\text { D\% } \\
\mathbf{2 0 1 0 / 2 0 1 4}\end{array}$ \\
\hline Pará & Estadual & 46.723 & 49.870 & 48.616 & 4,1 \\
\hline
\end{tabular}

Nota1: O mesmo aluno pode ter mais de uma matrícula.

Nota²: Os dados da tabela acima são números absolutos das matrículas da EJA médio.

Fonte: Brasil / INEP (2010, 2012 e 2014)

\section{Elaboração: OBEDUC (UFPA/UFPE/UFMG)}

Por isso, deve-se considerar a ampliação de vagas no ensino médio com a oferta da Educação de Jovens e Adultos (EJA) pelo Ministério da Educação - MEC, como uma de suas ações para o aumento da escolaridade de jovens e adultos. Isso pode causar, num primeiro momento, a elevação da distorção idade-série, decorrente, portanto, da ampliação de vagas e não da ineficiência das políticas públicas. 
Segundo o Censo Demográfico (2010), a população de 15 a 17 anos residente no Estado do Pará era de 486.649 pessoas, mas apenas 396.698 estavam estudando, ou seja, havia 89.951 jovens fora da escola, especialmente do ensino médio.

\section{- Sobre a Dimensão das Condições de Oferta do Ensino}

Com relação aos dados infraestrutura do Censo Escolar de 2014, foram utilizados os indicadores referentes à Alimentação, Serviços, Dependências, Equipamentos e Tecnologia, das escolas rurais e urbanas da Rede Estadual de Ensino Médio do Brasil, do Estado do Pará e das Regiões de Integração do Marajó e Metropolitana de Belém.

Antes de seguir com as análises, apresenta-se o número total de estabelecimentos por abrangência (País, Estado e Regiões). Segundo o Censo Escolar (2014), o Brasil possui um total de 19.009 escolas da rede estadual de nível médio, o Pará possui 528, sendo que apenas 29 estão no Marajó e 146 na região Metropolitana.

\section{- Alimentação}

Considera-se a situação de Alimentação Escolar essencial, já que muitos alunos de famílias muito pobres têm na alimentação escolar uma das poucas refeições do dia, se não a única. Ao se observar o Gráfico 1, identifica-se que a alimentação escolar foi universalizada no Brasil, o que significa avanço na busca da educação de qualidade, o que mostra o quanto o governo implementou em políticas públicas para obter esse resultado.

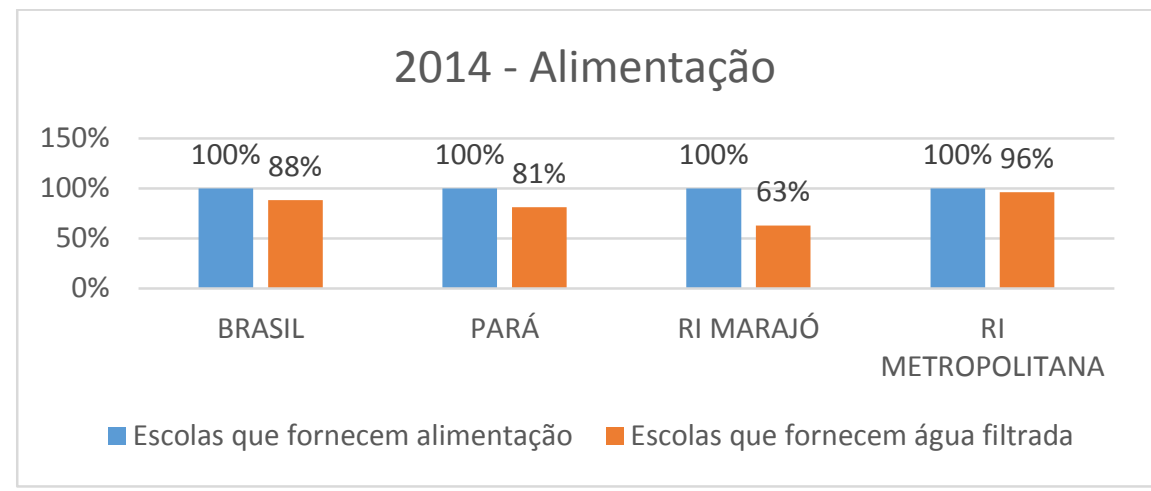

Fonte: Censo Escolar/INEP 2014

Elaboração: OBEDUC (UFPA/UFPE/UFMG) 
Quanto ao fornecimento de água filtrada, ainda há muito que ser feito, devido ao Brasil ser um país de grande extensão territorial, com florestas e climas semiáridos e possuir inúmeras regiões onde não há um saneamento básico adequado e muito menos água filtrada. Ao verificar o Gráfico 2 a seguir, pode ser notado que o Brasil possui uma taxa de 88\% (16.795 escolas) de escolas de ensino médio da rede estadual com água filtrada. Com 81\% (427 escolas) de escolas, o Estado do Pará ficou abaixo do percentual do país, o que já mostra que, em algumas escolas, pode haver água imprópria para o uso dos alunos.

Na região do Marajó, das 29 escolas, apenas 20 (ou seja, 63\% das escolas) possuem água filtrada. Essa região possui inúmeros desafios, pois está localizada numa região com muitos rios e florestas, o que dificulta a chegada de alguns avanços que parecem simples para quem vive nas grandes cidades. A região Metropolitana tem 96\% (142 escolas) das escolas com água filtrada, esse é um dado muito bom, mas que pode ser universalizado.

\section{- Serviços}

Neste tópico, destacam-se os dados referentes aos serviços públicos essenciais para o funcionamento da escola, como água, energia, esgoto e coleta de lixo, demonstrado no Gráfico 2.

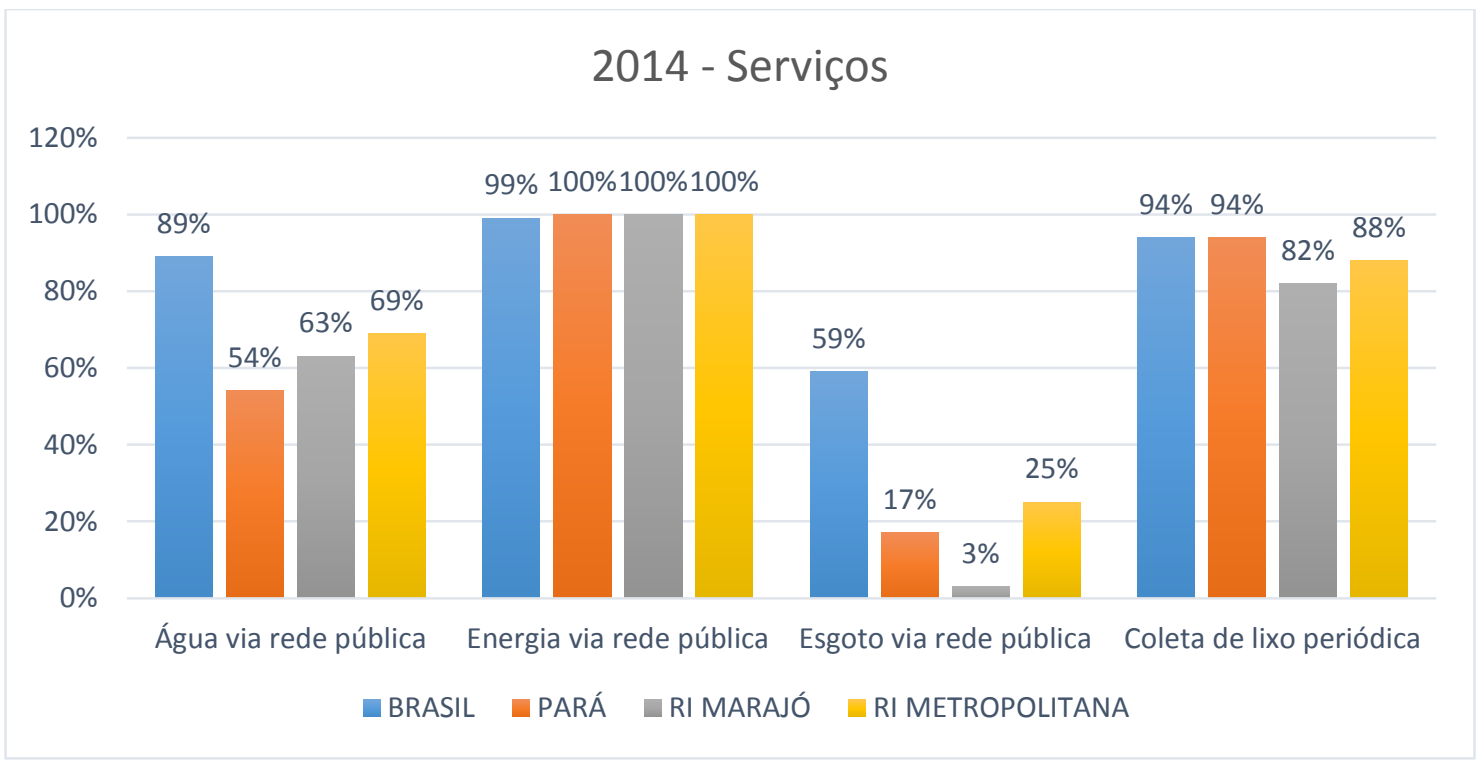

Fonte: Censo Escolar/INEP 2014

Elaboração: OBEDUC (UFPA/UFPE/UFMG)

O primeiro item a ser analisado é o serviço de água, cuja distribuição nacional atinge 89\% (16.839 escolas) nas escolas estaduais de nível médio. No Estado do Pará, essa realidade 
é muito diferente, pois apenas 54\% das escolas (286 escolas) possuem o abastecimento de água, ou seja, quase metade das escolas do Estado não tem um serviço mínimo, que é o abastecimento de água. Surge então a ideia de que, se os jovens não levarem água de casa, ficarão assistindo às aulas sem água.

Em relação às áreas marajoara e metropolitana, as mesmas possuem 63\% (18 escolas) e 69\% (102 escolas), respectivamente, de fornecimento de água da rede pública, o que nos mostra também uma precariedade desse serviço, que já deveria ter sido universalizado.

O segundo item é a energia elétrica da rede pública. Do total de escolas, 99\% (18.884 escolas) são atendidas no país. O Estado do Pará possui 100\% (528 escolas) no fornecimento de energia pública nas escolas, logo, as regiões de integração do Marajó e Metropolitana também estão com 100\% (29 e 146 escolas, respectivamente) desse serviço implantado nas escolas.

O Esgoto via rede pública é tido como o serviço mais precário prestado pelo poder público, pois apenas 59\% (11.225 escolas) das escolas do país possuem esgoto. Esses dados pioram quando analisamos a região Norte, especificamente o Pará, pois apenas 17\% (91 escolas) das escolas usufruem deste serviço. É difícil acreditar que, em pleno século XXI, ocorram situações como esta. Cabe, portanto, a observação acerca do slogan do governo do Estado, caracterizado pelos três "S", referindo-se um deles ao saneamento, esquecido, ao que parece, por parte do governo no que tange às escolas públicas.

O pior resultado é encontrado na região mais pobre do Estado, que é o Marajó, com apenas 3\% (1 escola) das escolas atendidas por este serviço. Isto é triste: apenas uma escola do Marajó possui esgoto. A região Metropolitana, embora esteja numa área mais urbanizada, não possui uma taxa tão boa assim, já que apenas $25 \%$ das escolas (69 escolas) têm esse serviço. O que evidencia como o Estado investe pouco para a melhoria do saneamento básico nas escolas.

Por fim, o último item, a ser analisado no Gráfico 2, é o da coleta de lixo. Um percentual de 94\% (17.824 escolas) das escolas estaduais de nível médio do Brasil possuem o serviço da coleta de lixo. O Pará também possui 94\% (498 escolas) desses serviços. O Marajó foi a região que apresentou a menor taxa, com apenas $82 \%$ ( 24 escolas) da coleta de lixo nas escolas. A região Metropolitana de Belém possui também um indicador menor que a média nacional e estadual, de $88 \%$ (144 escolas). 


\section{- Dependências}

No Quadro 1, apresentam-se as dependências das escolas, focamos em seis categorias que achamos relevantes: biblioteca, laboratório de informática, laboratório de ciências, quadra de esportes, sala de leitura e sala para atendimento especial. A infraestrutura da escola é peça chave para a prática de uma educação de qualidade.

\section{QUADRO 1 - Censo Escolar}

\begin{tabular}{|c|c|c|c|c|}
\hline \multicolumn{5}{|c|}{ Dependências } \\
\hline Abrangência & BRASIL & PARÁ & RI Marajó & $\begin{array}{c}\text { RI } \\
\text { Metropolitana }\end{array}$ \\
\hline Biblioteca & $\begin{array}{c}\mathbf{6 6 \%}(12.481 \\
\text { escolas) }\end{array}$ & $\begin{array}{c}\text { 73\% (385 } \\
\text { escolas) }\end{array}$ & $\begin{array}{l}\mathbf{7 3 \%}(20 \\
\text { escolas) }\end{array}$ & $\begin{array}{c}\mathbf{7 0 \%}(122 \\
\text { escolas) }\end{array}$ \\
\hline $\begin{array}{l}\text { Laboratório de } \\
\text { informática }\end{array}$ & $\begin{array}{l}\mathbf{9 0 \%}(17.090 \\
\text { escolas) }\end{array}$ & $\begin{array}{c}\mathbf{8 0 \%}(425 \\
\text { escolas) }\end{array}$ & $\begin{array}{l}\mathbf{8 4 \%}(24 \\
\text { escolas) }\end{array}$ & $\begin{array}{c}\mathbf{8 7 \%}(125 \\
\text { escolas) }\end{array}$ \\
\hline $\begin{array}{l}\text { Laboratório de } \\
\text { ciências }\end{array}$ & $\begin{array}{c}\mathbf{4 3 \%}(8.246 \\
\text { escolas) }\end{array}$ & $\begin{array}{c}\mathbf{4 5 \%}(240 \\
\text { escolas })\end{array}$ & $\begin{array}{l}\mathbf{5 4 \%}(15 \\
\text { escolas) }\end{array}$ & $\begin{array}{l}\mathbf{4 8 \%}(73 \\
\text { escolas) }\end{array}$ \\
\hline Quadra de esportes & $\begin{array}{c}\mathbf{7 6 \%} \text { (14.362 } \\
\text { escolas) }\end{array}$ & $\begin{array}{c}\mathbf{7 0 \%}(367 \\
\text { escolas) }\end{array}$ & $\begin{array}{l}\mathbf{6 2 \%}(18 \\
\text { escolas) }\end{array}$ & $\begin{array}{c}\mathbf{7 2 \%}(120 \\
\text { escolas) }\end{array}$ \\
\hline Sala para leitura & $\begin{array}{c}32 \%(6.015 \\
\text { escolas) }\end{array}$ & $\begin{array}{c}\mathbf{3 0 \%}(157 \\
\text { escolas })\end{array}$ & $\begin{array}{l}\mathbf{3 7 \%}(8 \\
\text { escolas) }\end{array}$ & $\begin{array}{l}32 \%(55 \\
\text { escolas) }\end{array}$ \\
\hline $\begin{array}{c}\text { Sala para } \\
\text { atendimento } \\
\text { especial }\end{array}$ & $\begin{array}{c}\mathbf{2 5 \%}(4.769 \\
\text { escolas) }\end{array}$ & $\begin{array}{c}\mathbf{2 4 \%}(126 \\
\text { escolas })\end{array}$ & $\begin{array}{l}10 \%(3 \\
\text { escolas) }\end{array}$ & $\begin{array}{l}\mathbf{3 8 \%}(58 \\
\text { escolas) }\end{array}$ \\
\hline
\end{tabular}

Fonte Censo Escolar/INEP 2014 | Total de Escolas de Educação Básica: 19.009 |

QEdu.org.br

Elaboração: OBEDUC (UFPA/UFPE/UFMG)

O item Biblioteca é uma ferramenta essencial em uma escola, pois é por meio dela que os alunos podem se aproximar mais da leitura e da pesquisa, e os professores podem utilizála para sua prática pedagógica. Mas se constata uma realidade nacional em que apenas $66 \%$ das escolas estaduais de nível médio possuem uma biblioteca. Diferentemente do restante do Brasil, o Estado do Pará possui $73 \%$ de suas escolas equipadas com bibliotecas. A Região do Marajó obteve os mesmos 73\%, e a Região Metropolitana com 70\% das escolas equipadas com biblioteca, o que mostra que foi feito um trabalho para equipar as escolas estaduais com essa ferramenta, mas ainda há muitas escolas sem bibliotecas. 
O segundo item é o Laboratório de Informática, um excelente material didático e ferramenta de pesquisa para alunos e professores. Além de ser um meio de inclusão social, já que muitos alunos não têm acesso à banda larga em casa, e a escola, muitas das vezes, é o local onde esse acesso é gratuito e acessível. Com base nos dados, pode-se concluir que $90 \%$ das escolas estaduais de nível médio no Brasil possui laboratório de informática, um avanço conquistado junto ao Programa Nacional de Tecnologia Educacional - PROINFO $^{4}$, um programa do governo Federal. No Pará, esse número cai para 80\%. A região do Marajó possui $84 \%$, e a Metropolitana com 87\%. Mas ainda há muito o que avançar com relação a esse serviço.

Quanto ao Laboratório de Ciências, a universalização é uma realidade distante nas escolas estaduais de nível médio, o que dificulta muitas vezes a prática de se fazer pesquisa e de o aluno atuar, na prática, como pesquisador. No Brasil, apenas $43 \%$ das escolas possui um laboratório de ciências, o que nos mostra que pouco é investido na educação básica de nível médio quanto à produção de ciência de modo a incentivar os jovens a realizarem pesquisa científica. No Estado do Pará, 45\% das escolas contam com laboratórios um pouco quantitativamente acima da média nacional.

Nas regiões de integração, o Marajó, apesar de ser uma região mais pobre, se mostrou mais equipado com relação a esse item, com 54\% das escolas equipadas, enquanto que a região Metropolitana possui apenas $48 \%$ de suas escolas com laboratório de ciências. Em uma sociedade moderna, isso faz muita falta.

Quanto à estrutura para a prática de esportes, essencial para a formação de qualidade e desenvolvimento do aluno, no Brasil, 76\% das escolas possui Quadra de Esportes, enquanto o Pará possui 70\% de escolas com este item. Na região do Marajó, 62\% das escolas têm quadra de esportes, e na região Metropolitana, $72 \%$ das escolas são esquipadas com esta ferramenta de ensino-aprendizagem. É contraditório se pensar que o nosso país, no ano de 2016, sediou as Olimpíadas, e muitos jovens, principalmente da zona rural, sequer têm um espaço para a prática de esportes.

Outra ferramenta importante para a construção de uma educação de qualidade é a Sala para Leitura, que irá contribuir para formar alunos mais interessados em ler e escrever sobre os mais diversos assuntos. Mas, quando se observam os dados no Quadro 12, pode ser verificado que pouco é investido nessa ferramenta de estudo. Somente 32\% das escolas estaduais de nível médio do Brasil possuem salas para leitura. No Pará, esse número baixa para

\footnotetext{
${ }^{4}$ É um programa educacional com o objetivo de promover o uso pedagógico da informática na rede pública de educação básica. 
30\%. A região do Marajó encontra-se com 37\% de escolas com esse item, um pouco melhor que a região Metropolitana, que apresenta $32 \%$ das escolas com sala para leitura.

Dados que mostram também o porquê de os alunos do ensino médio do Pará estarem ocupando os últimos lugares no ranking da prova Brasil, pois não há espaços na escola que estimulem os alunos a ler. É preciso haver um investimento maior por parte do Governo Federal, em conjunto com os estados e municípios, para afirmar políticas públicas de incentivo à leitura e de criação de espaços para leitura, para que, assim, o aluno venha a ter seu interesse despertado para essa prática.

Por fim, destaca-se a Sala para Atendimento Especial, pois pensar em ter uma educação com igualdade de acesso para todos passa por se pensar também em dar acesso aos jovens com deficiência. É importante que todas as escolas venham a ter uma sala de atendimento especial para assistir esses alunos. O que se observa é que essa presença está muito distante das escolas, pois apenas 25\% das escolas do Brasil, da rede estadual de nível médio, possuem alguma sala para receber alunos com deficiência. Fica a se pensar como as outras $75 \%$ das escolas recebem seus alunos especiais. No Estado do Pará, essa realidade é ainda pior, com apenas $24 \%$ das escolas dispondo da sala para esse atendimento. E, nas regiões de integração, o Marajó é a que se encontra em pior situação, com apenas 10\%, ou seja, 3 escolas, com uma sala de atendimento especial. Como falar de Qualidade na Educação se o governo não garante o acesso e permanência a todos os jovens? Fica a indagação. Na região Metropolitana, o registro também é insuficiente: $38 \%$ das escolas possuem uma sala de atendimento especial. Nota-se novamente que não é possível falar em uma escola que é igual para todos, com isso os alunos especiais não conseguem ter um desenvolvimento intelectual desejável.

\section{- Equipamentos}

No Quadro 2, estão listados os equipamentos mínimos que uma escola deveria ter e, em nossa análise, focamos em apenas em três equipamentos: o aparelho de DVD, a Máquina Copiadora e o Retroprojetor, pois os mesmos são ferramentas essenciais na prática pedagógica e na didática da aula do professor. 


\section{QUADRO 2 - EQUIPAMENTOS}

\begin{tabular}{|c|c|c|c|c|}
\hline \multicolumn{5}{|c|}{ Equipamentos } \\
\hline Abrangência & BRASIL & PARÁ & RI Marajó & $\begin{array}{c}\text { RI } \\
\text { Metropolitana }\end{array}$ \\
\hline $\begin{array}{l}\text { Aparelho de } \\
\text { DVD }\end{array}$ & $\begin{array}{c}90 \% \text { (17.086 } \\
\text { escolas) }\end{array}$ & $\begin{array}{c}89 \%(471 \\
\text { escolas) }\end{array}$ & $\begin{array}{l}84 \%(24 \\
\text { escolas) }\end{array}$ & $\begin{array}{c}91 \%(139 \\
\text { escolas) }\end{array}$ \\
\hline $\begin{array}{l}\text { Máquina } \\
\text { copiadora }\end{array}$ & $\begin{array}{c}71 \% \text { (13.560 } \\
\text { escolas) }\end{array}$ & $\begin{array}{c}40 \%(213 \\
\text { escolas) }\end{array}$ & $\begin{array}{l}32 \%(12 \\
\text { escolas) }\end{array}$ & $\begin{array}{l}25 \% \text { (59 } \\
\text { escolas) }\end{array}$ \\
\hline Retroprojetor & $\begin{array}{c}71 \%(13.540 \\
\text { escolas) }\end{array}$ & $\begin{array}{c}63 \%(334 \\
\text { escolas) }\end{array}$ & $\begin{array}{l}53 \%(16 \\
\text { escolas) }\end{array}$ & $\begin{array}{l}79 \%(110 \\
\text { escolas) }\end{array}$ \\
\hline
\end{tabular}

Fonte Censo Escolar/INEP 2014 | Total de Escolas de Educação Básica: 19.009 |

QEdu.org.br

Elaboração: OBEDUC (UFPA/UFPE/UFMG)

O primeiro item a ser analisado é o Aparelho de DVD, equipamento comum nos estabelecimentos escolares, embora haja escolas estaduais de nível médio que não o possuem. No Brasil, 90\% das escolas possuem tal aparelho, e, no Pará, esse número cai para 89\%. Nas regiões de integração do Estado do Pará, a do Marajó conta com 84\% das escolas com, pelo menos, um aparelho DVD, e, na região Metropolitana, esse número sobe para $91 \%$.

Um item que chama atenção foi a máquina copiadora, que é o equipamento no qual o professor e os alunos podem fazer suas cópias de material didático ou complementar aos estudos. No Brasil, apenas $71 \%$ das escolas possui tal recurso. No Pará, esse item é escasso, havendo apenas $40 \%$ de escolas que se utilizam deste aparelho, ou seja, menos da metade. No Marajó, apenas 32\% dos estabelecimentos possuem o equipamento, ou seja, das 29 escolas de estaduais de nível médio que existem na ilha, apenas 12 possuem essa máquina, o que nos leva a pensar que os alunos, muitas vezes, tendem a copiar de forma manuscrita ou fazem cópias fora da escola. A região Metropolitana, que deveria ter esse equipamento disponibilizado com certa regularidade, é a que menos o tem disponível nas escolas, com apenas $25 \%$ das escolas com esse equipamento. O que é uma contradição, já que, segundo o Censo 2014, 100\% das escolas da rede estadual de nível médio possuem uma impressora.

No Brasil, 71\% das escolas possuem o retroprojetor, o que já é um avanço, mas que deve ser melhorado. No Pará, ainda se identifica que poucas são as escolas que têm tal aparato: apenas $63 \%$. Na região do Marajó, esse equipamento se torna mais escasso, já que $53 \%$ das escolas detêm esse equipamento, um item que, por suas especificidades, é de grande valia para 
uma região como o Marajó. Por outro lado, a região Metropolitana apresenta uma taxa de 79\% de escolas que possuem um retroprojetor.

\section{- Tecnologia}

No Gráfico 3, verifica-se o uso da tecnologia nas escolas. Grande parte da população usa a internet como meio de comunicação e aprendizagem, através das redes sociais, aplicativos, jogos, pesquisas, entre outras ferramentas. Sem a tecnologia, é difícil a comunicação, e, na escola, não é diferente. Uma ferramenta chave é o uso do computador com Banda Larga. Mas ainda há escolas em que o Estado não disponibilizou o uso dessa ferramenta, como pode ser notado a seguir.

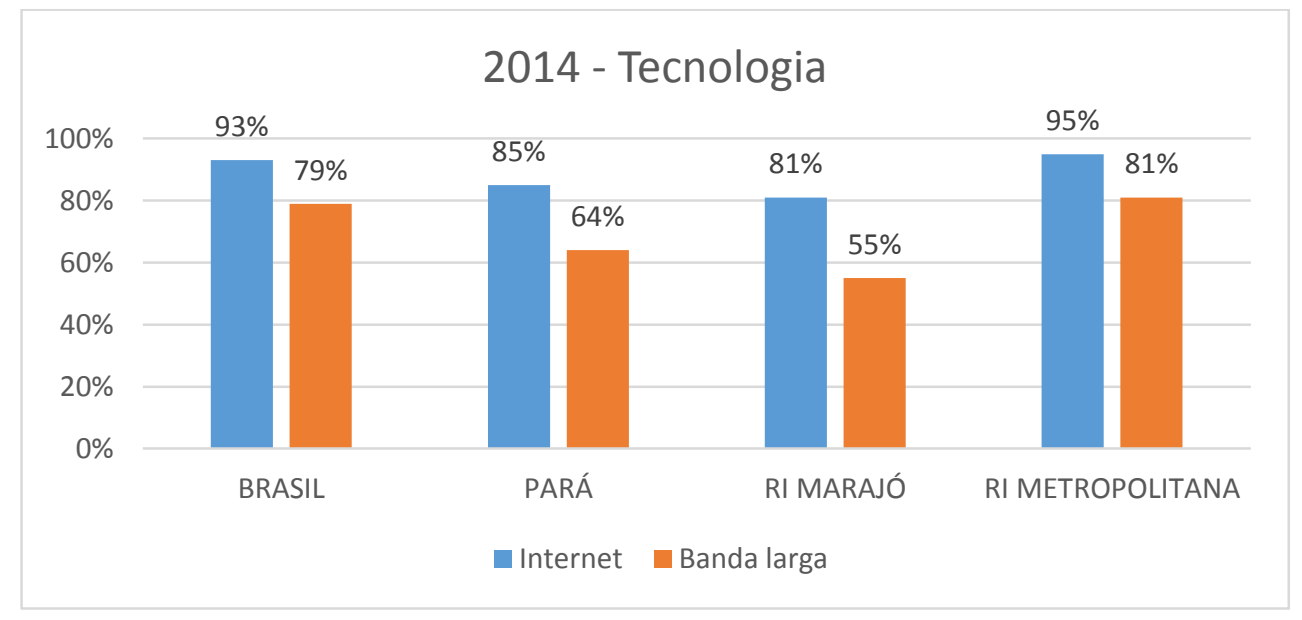

Fonte: Censo Escolar/INEP 2014

Elaboração: OBEDUC (UFPA/UFPE/UFMG)

O uso da internet atinge $93 \%$ das escolas estaduais de nível médio no Brasil, o que já é um avanço. No Pará, $85 \%$ das escolas usufruem desta tecnologia, mas ainda há que se avançar quanto a possibilitar o acesso à internet aos jovens. Nas regiões de integração, esse dado mostra que há diferenças no acesso de uma região para outra. No Marajó, 81\% das escolas têm esse acesso, e na Metropolitana, esse dado salta para 95\%. O que evidencia que foi feito um trabalho, por parte do governo, mais abrangente nas áreas com maior densidade populacional e urbanização.

Quando se analisa a disponibilidade da Banda Larga (conexão de internet em alta velocidade), uma ferramenta mais ágil, verifica-se que, no Brasil, essa disponibilidade atinge $73 \%$ das escolas, e, no Pará, esse dado é menor, com $64 \%$ somente das escolas com esse item. Observa-se que há uma grande diferença de disponibilidade desse serviço nas regiões de 
integração, por parte do Estado. Na região do Marajó, apenas 55\% das escolas possuem Banda Larga, enquanto na Metropolitana esse dado sobe para $81 \%$. Portanto, falta maior investimento público na região do Marajó.

Outro dado que evidencia a escassez de investimento do governo estadual em tecnologia é o número de computadores por aluno. Segundo o Censo Escolar de 2014, no Marajó, existe um computador para cada 44 alunos, e, na região Metropolitana, não é muito diferente, há um computador para 39 alunos, muito pouco, considerando a demanda por esse tipo de ferramenta. Destacando que esses dados são apenas das escolas estaduais de nível médio.

Destaca-se que a população jovem, de faixa etária entre 15 a 17 anos, residente no Estado do Pará, 89.951 jovens estão fora da escola. Outro problema detectado se refere à precariedade das condições de acesso dos nossos estudantes a inúmeros serviços públicos na escola, como a pouca oferta de laboratórios e quadras de esporte, quase nenhuma sala de atendimento especializado para alunos com deficiência, infraestruturas precárias, escassez de equipamentos para auxiliar a prática do professor em sala de aula, disponibilidade de acesso à Internet, sem contar a quantidade de computadores por aluno.

Todos esses são problemas que dificultam a oferta de uma educação de qualidade. Com isso, afirma-se que a educação de nível médio no Estado do Pará não está bem no que diz respeito à garantia do direito à educação e à universalização do ensino médio. Em síntese, os indicadores apontam para uma precariedade quanto à questão da não qualidade do acesso no ensino médio ofertado pelo governo do Estado do Pará. O que se pôde constatar foi que, independentemente de abordar a região pobre ou a rica, ambas possuem dados muito parecidos, sejam na reprovação ou no abandono, havendo pequenas diferenças no que tange à questão da infraestrutura.

\section{Algumas considerações}

O presente estudo abordou os indicadores educacionais do INEP, com o intuito de verificar como vem sendo garantida a oferta do ensino médio público estadual nas Regiões de Integração do Marajó e área Metropolitana de Belém/PA. Como resposta a essa finalidade destacam-se os seguintes resultados.

Da população de 15 a 17 anos residente no Estado do Pará, segundo o Censo Demográfico de 2010, 89.951 mil jovens estão fora da escola, especialmente do ensino médio. 
Outro problema evidenciado foi a precariedade das condições de acesso dos nossos estudantes a inúmeros serviços públicos na escola. Reduzida quantidade de laboratórios e quadras de esporte, quase nenhuma sala de atendimento especializado para alunos com deficiência, infraestruturas precárias, escassez de equipamentos para auxiliar a prática do professor em sala de aula, disponibilidade de acesso à Internet, sem contar a quantidade de computadores por aluno. Todos esses são problemas que dificultam a oferta de uma educação de qualidade, o que redunda em abandono ou reprovação pelos alunos.

Diante dessa realidade, conclui-se que muitos jovens que dependem do ensino público são alijados do processo educacional, o que compromete seu direito social básico, educação básica obrigatória, gratuita e de qualidade. É notória a deficiência do Governo no Estado do Pará quanto ao investimento em políticas públicas que façam uma intervenção eficiente e urgente na educação da classe que mais sofre com isso, a trabalhadora.

Em síntese, os dados são reveladores da atual situação da educação pública dessa etapa de ensino ofertada pela Secretaria Estadual de Educação do Pará, em especial nas regiões do Marajó e Área Metropolitana de Belém. O Governo do Estado Pará não consegue suprir necessidades básicas dentro das escolas, como a garantia de água filtrada, esgoto e água, via rede pública, entre outras coisas. Com isso, não é possível falar em qualidade da educação se o Estado não consegue garantir também bibliotecas, quadra de esportes, laboratórios para os alunos da rede pública de ensino. Desse modo, enfatiza-se que não há qualidade de acesso ao ensino ofertado pelo governo estadual.

Ressalta-se que uma alternativa à solução desse grave problema educacional seria o de grandes investimentos por parte do Governo do Pará em educação de nível médio básico com qualidade. Outra possibilidade seria a oferta da educação integral (na perspectiva de atender às necessidades do público que frequenta a educação publica - a classe trabalhadora) rumo à construção de uma educação com qualidade para nossa juventude trabalhadora.

\section{Referências}

BRASIL. Instituto Nacional de Estudos e Pesquisas Educacionais Anísio Teixeira (INEP) Brasília: INEP. Indicadores Educacionais. 2014. Disponível em:<http://portal.inep.gov.br/indicadores-educacionais>. Acesso em: 10 nov. 2014.

Instituto Brasileiro de Geografia e Estatística (IBGE) - Brasília. IBGE Cidades.

Disponível em: http://www.ibge.gov.br. Acesso em: 11, nov de 2015. 
DOURADO, L. F; OLIVEIRA, J. F; SANTOS, C. A. A qualidade da educação: conceitos e definições. Série Documental (INEP), Brasília, v. 24, n.22, p. 05-34, 2007.

FRIGOTTO, CIAVATTA, RAMOS (Org.). Ensino Médio Integrado: Concepção e Contradições/ São Paulo, Cortez, 2005.

PARÀ. Secretaria de Estado de Planejamento. Documento de Referência para Elaboração do PPA 2016-2019. Belém, SEPLAN, 2015. 